\title{
Making the Case for Community Health Workers in Georgia
}

Gail G. McCray, MA, MCHES'1, Berneta L. Haynes, JD², Adrianne S. Proeller, BA³, Christopher E. Ervin, MD³, and Arletha D. Williams-Livingston, $\mathrm{PhD}, \mathrm{MPH}, \mathrm{MBA}^{3}$

${ }^{1}$ Morehouse School of Medicine, Department of CHPM, ${ }^{2}$ Georgia Watch and ${ }^{3}$ Morehouse School of Medicine

Corresponding Author: Gail G. McCray, MA, MCHES • Morehouse School of Medicine, Department of Community Health and Preventive Medicine $\cdot 720$ Westview Dr, Atlanta, GA 30310・Telephone: (404) 752-1645•Email: gmccray@msm.edu

\section{ABSTRACT}

Background: Community Health Workers (CHW) can be an important and evidence-based response to reduce unnecessary morbidity and mortality in chronic diseases like asthma, heart disease, diabetes, cancers, HIV, and maternal/child health, and mental health. Georgia's urban and rural diverse populations are at high risk from many of these conditions. Largely the contributors to the poor outcomes for these health issues are non-medical and include social determinants of health, i.e., access to care, transportation, inadequate housing, and health literacy. CHWs can increase the capacity of individuals, families, and communities to improve their health. Historically, concerns of CHWs on healthcare teams to address these issues have centered on standardized training, credentialing, and challenges about the unique roles and responsibilities of CHWs. In this article, we discuss the evidence of effectiveness and return on investment as CHW interventions prove to reduce visits to the Emergency Departments and unnecessary hospitalizations from chronic diseases. They serve to connect social and medical resources and ensure patients do not fall through gaps, especially among the vulnerable populations.

Methods: We conducted a scan of CHW research studies, projects and programs that demonstrate effectiveness and return on investment. We also reviewed CHW efforts in Georgia, timeline, and stakeholders to formally recognize, advance professionalism, and fully integrate CHWs as essential and sustainable members of the healthcare team.

Results: There is significant evidence for the effectiveness of CHWs and the cost-benefit of CHW programs. Georgia has ongoing formal efforts to establish a sustainable and well-trained CHW workforce.

Conclusions: A well-trained CHW workforce can be an important response to the transformation of Georgia's community health practice and status, decreasing excess morbidity and mortality, and advancing health equity. Georgia should build on its own considerable experience with $\mathrm{CHWs}$ and the evidence of effectiveness to adopt policies to fully integrate CHWs into the healthcare system.

Keywords: Community health workers, social determinants of health, healthcare teams, ROI and CHWs, financial stability and CHW Programs, Medicaid and CHWs

\section{INTRODUCTION}

Health, healthcare delivery, and healthcare financing are high priority topics that dominate our news, politics and policymaking, academic and institutional research and education, and just plain everyday kitchen table-talk. The impact of the recent novel Coronavirus disease (COVID-19) pandemic has brought greater attention to existing healthcare disparities and health inequities among income groups, urban and rural populations, race/ethnicity, and those who are insured and who have inadequate health insurance (APM Research, 2020). In Georgia, there are high rates of death and disability that existed pre-COVID-19 from chronic diseases like heart disease, cancers, asthma, hypertension, and stroke (Bayakly, 2015). Tragically, Georgia rates 49 of the 50 states in rates of maternal and child death (America's Health Rankings [AHR], 2019). Although there have been some improvements in important areas over the past several years -- a 13\% increase in high school graduation rates, $8 \%$ decrease in smoking rates, $12 \%$ increase in mental health providers, and $13 \%$ decrease in violent crimes -- the same report gave Georgia an overall health ranking of 40 among the 50 states. Much of the suffering from these conditions is preventable (AHR, 2019). It is unacceptable that people in the United States and Georgia especially continue to suffer unnecessarily from preventable chronic diseases and health conditions in one of the wealthiest countries in the world. We know there is no single answer to this problem. There is a need for major transformations in our health systems to eliminate racial and ethnic disparities and to advance health equity. In this article, we will focus on the ongoing work in Georgia to 
implement the formal integration of the Community Health Worker (CHW) workforce as integral members of the healthcare team as one major strategy and solution to reduce excess morbidity and mortality in the state. There is evidence from decades of research and practice that demonstrates the deployment of CHWs can help to mitigate unnecessary suffering and that they are an underutilized resource in the transforming of the health status of communities across this country, and most especially in the state of Georgia.

"Community Health Worker" is an umbrella term and the more commonly accepted term that refers to people who are also known as outreach workers, promotores(as) de salud, community health representatives, lay health workers, peer educators, patient/client navigators, and more than 20 other titles, according to the 2007 report from the Health Services and Research Administration (HRSA, 2007). At the time of this report entitled Community Health Workers National Workforce Study CHWs made up a workforce of an estimated 86,000 in the United States (HRSA, 2007). In that report, the estimated number of $\mathrm{CHWs}$ in Georgia was approximately 3,250. This number included both wage earners (67 percent) and volunteers (33 percent) in not-for-profit and for-profit organizations such as schools, universities, clinics, hospitals, physician offices, individual-family-child services, and educational programs (HRSA, 2007). CHWs have historically been hired with temporary funding through grants, generally for three - five years, and are, unfortunately, likely to lose their employment when the grant ends, no matter if the intervention was shown to be successful.

In 2009, the Bureau of Labor Statistics (BLS), U.S. Department of Labor, recommended the creation of a Standard Occupational Classification (SOC) for CHWs. This job classification was subsequently included in a provision of the 2010 landmark national health reform law, the Patient Protection and Affordable Care Act (PPACA) (BLS, 2009)). The PPACA includes several sections that recognize the key roles for CHWs in achieving important goals of health care (Rosenthal, et al, 2010) (PPACA, 2010). It highlights the effectiveness of CHWs in reducing morbidity and mortality in asthma, maternal and child health, and asthma. The PPACA points to evidence of CHWs in controlling medical care costs through reduced hospitalizations. With an appointed job classification for CHWs and support from the PPACA already in place, some potential hurdles that would inhibit the financial sustainability of this workforce through payment for their services have already been overcome. CHWs can be paid for their services through third-party payers, including Medicaid (Albritton, 2016).

\section{CHW Background/History}

According to the previously mentioned HRSA report (2007), the documented history of CHWs in the United
States goes back to the 1960s when CHWs were deployed through the 1962 Federal Migrant Act, as "neighborhood health aides" to combat high incidence of disease and death from tuberculosis. Through the decades, a rich body of evidence has been accumulating on the effectiveness and cost-effectiveness of CHWs. Globally, the CHW workforce evolved in Asia and Africa, where greater access to traditional medical support was needed, but not available (Werner, 1970). In the United States, there was a similar evolution where medical care was not accessible, affordable, or available to large segments of the population whether urban or rural because of reasons like inadequate insurance, lack of enough providers in the geographic area, or knowledge about how to access the system.

CHWs grew as a workforce with a primary responsibility of reducing non-medical barriers to health, like transportation, language barriers, housing, racism, health literacy, and access to healthy foods -- or the social determinants of health (SDoH) (CDC, 2018). According to the World Health Organization, SDoH are "the conditions in which people are born, grow, live, work and age. These circumstances are shaped by the distribution of money, power and resources at global, national and local levels" (World Health Organization, 2012). While the training and employment of CHWs is not an innovation today, it is a job category that has been widely misunderstood and sometimes seen as a duplication of the traditional jobs of nurses or social workers. Indeed, some of the more than 30 titles have been adopted as new job categories for nurses and social workers, including Nurse Navigators or Social Worker Navigators (HRSA, 2007). To clarify, CHWs are the "in-between" people as they are referred to in some native American communities (Satterfield et al., 2002), or promotoras de salud (health promoters) in the Latinx community. They are known as the bridge or connector "in-between" the medical environment, social services, and the community to reduce any gaps in healthcare delivery services. (American Public Health Association [APHA], 2020).

CHWs complement the well-established roles of physicians, nurses, nurse practitioners, physicians' assistants, therapists and social workers. CHWs do not diagnose, but make sure the patients understand the diagnosis. CHWs do not prescribe medicines or treatments but work with the patient to reduce barriers that prevent the patient from following physician's instructions. CHWs help patients or clients more successfully connect with the resources social workers might provide. They generally spend more time with clients than other healthcare providers and can report signs and symptoms of health conditions for which they are specifically trained. Some CHWs conduct home visits or are community-based and might alert the healthcare team that a patient might be showing signs of depression or provide resources where the patient might receive counseling. As a trusted member of the community, a $\mathrm{CHW}$ facilitates important discussions, may help to improve patient-doctor communications, and enables better health outcomes. 
The CHW workforce has become more widely accepted in recent years, partially in response to the continued rising costs in healthcare along with uncontrolled chronic diseases like diabetes and hypertension. Increasing costs, in part, are a result of having the uninsured use Emergency Department (ED) as primary care clinics, or increased ED visits and increased hospitalizations due to the inability or refusal of the patient to follow instructions of the provider, and late diagnosis of disease (Kangovi et al., 2015). Kangovi et al. (2019) explain that the reliance on an old model of healthcare with a doctor, nurse, and providing expensive prescriptions have not caught up with population needs of having nonmedical issues resolved for the best health outcomes. These are inefficient features of the healthcare system that must take advantage of the research and transform the current system.

CHWs support patients, caregivers, and their families as patients are now expected to take on more responsibility of self-monitoring or self-management of their disease. While demands for physician's time to complete Electronic Health Records and insurance paperwork increases, the time to spend with patients declines. The time for the average primary care provider or specialty visit is estimated at $8-15$ minutes (Lee, 2016). This limited amount of time can damage the patient-doctor relationship and the capacity to provide clear two-way communications about the health condition, what is expected of the patient and why, and to assess whether the patient has the capacity to follow the instructions. CHWs can take more time to walk with patients through the steps needed to maintain their health and listen to patient concerns, sometimes in a more patient-friendly language and often in the comfort of their own home or community environment. $\mathrm{CHWs}$ can complete the circle of communication with the medical staff, if appropriate, and help to identify and reduce other possible barriers to achieving optimal health.

Georgia can benefit from changes in its approaches to the prevention and control of our high prevalence of chronic diseases and their sequelae (Bayakly, 2015). We have the knowledge. We have the power. We have the experience. We have made some major strides in the direction of placing CHWs in clinics, hospitals, and communities to achieve the Triple Aim of health care - improved population health, improved patient experience, and reduced costs of healthcare (Institute for Health Improvement (IHI), 2015). What is needed more is the will of Georgia health professionals, policymakers, and residents to create policy that will establish a sustainable CHW model with reimbursement of their services.

\section{Definitions of $\mathrm{CHWS}$}

The definitions of CHWs from APHA, BLS, and the state of Georgia have slight variations, but more features in common. The BLS describes CHWs as those who: assist individuals and communities to adopt healthy behaviors; conduct outreach for medical personnel or health organizations to implement programs in the community that promote, maintain, and improve individual and community health; provide information on available resources, provide social support and informal counseling, advocate for individuals and community health needs, and provide services such as first aid and blood pressure screening; and collect data to help identify community health needs. (SOC, BLS - 21-1094, 2010). This definition was slightly modified from the one submitted to BLS by APHA and is regularly updated to reflect the work of CHWs.

Parts of the definition from APHA that are considered to be part of the basic fabric of CHWs was generated from years of research on $\mathrm{CHW}$ qualities, characteristics, roles and responsibilities (Rosenthal et al., 1998). The definition includes that a CHW is a "frontline public health worker who is a trusted member of and/or has an unusually close understanding of the community served. This trusting relationship enables the worker to serve as a liaison/link/intermediary between health/social services and the community to facilitate access to services and improve the quality and cultural competence of service delivery. A community health worker also builds individual and community capacity by increasing health knowledge and self-sufficiency through a range of activities such as outreach, community education, informal counseling, social support and advocacy" (APHA, 2020).

The development of the definition of CHWs took many years of research and discussions on existing CHWs in the U.S. by a national CHW Task Force. It demonstrates the uniqueness of this front-line health worker in several ways. Notably, this health worker builds relationships and trust with the communities they serve even before they are needed. They also work to build individual and community capacity, so that there is greater patient or client knowledge and capacity to navigate the healthcare system after successful interactions with CHWs.

\section{METHODS}

There is a concerted effort to establish an evidence-based and financially sustainable $\mathrm{CHW}$ workforce and model program in the state of Georgia in an effort to reduce preventable morbidity and mortality and the related unnecessary suffering. A documented timeline for CHWs presence and effectiveness in Georgia follows.

Some of the first publications of CHWs in research and practice in Georgia were on the use of "lay health workers" to assess and reduce mortality from breast and cervical cancer in African American women (Sung et al., 1992; Sung et al., 1997). In 2000, efforts were focused on developing a training curriculum for CHWs with a special emphasis on CHWs who worked in primary prevention to increase breast and cervical cancer screening through the Georgia 
Department of Public Health (GaDPH). The GaDPH, the American Cancer Society/Southeast Division, and the Department of Community Health and Preventive Medicine (CHPM), Morehouse School of Medicine collaborated to develop and implement the first competency-based curriculum to train all CHWs (McCray, Personal Communication, May 9, 2020). The first class of 27 CHWs graduated with a certificate signed jointly by leadership of the three entities - Dr. Daniel Blumenthal, as Chair of the Department of CHPM, Dr. Kimberly Redding for GaDPH, and Morgan Daven, for the American Cancer Society, Southeast Division (McCray, Personal Communication, May 9, 2020). Cancer control and prevention programs had the most visible CHW programs at that time, though as we cast a net, we found many more CHWs representing many disease areas. Maternal and child health, HIV control, sickle cell, doulas, public health department workers in parenting programs, STI programs, diabetes and hypertension control were among the groups (McCray, Personal Communication, May 9, 2020). Between 2002 and 2008, representatives from more than 30 health agencies and organizations came together and formed the Georgia CHW Network. This Group met regularly during this period, helped to identify priority areas of interest, and were instrumental in planning and implementing a statewide reconnaissance on CHWs with funding from the Healthcare Georgia Foundation. A couple of major findings from the reconnaissance included that there were at least 20 different names by which CHWs were called in Georgia and that almost every entity had their own training program to implement their specific program. Most were not competency-based and were developed to train the CHWs for program-specific tasks. Those issues aligned with the national CHW concerns, and included standardized training, credentialing of $\mathrm{CHWs,} \mathrm{regularly}$ scheduled trainings and sites, formal recognition, competitive salaries, and plans for sustainability. The Georgia regional Cancer Coalitions employed CHWs, and strongly voiced similar concerns as they experienced high attrition rates when their well-recruited and well-trained workforce left for better paying job opportunities. In 2008, we formed a Georgia Community Health Worker Network, and held the first statewide CHW Forum in November 2008 in Callaway Gardens with approximately 120 participants (McCray, Personal Communication, May 2020). Over the years, more than $350 \mathrm{CHWs}$ from academic institutions, Cancer Centers of Excellence, the United Way of Metropolitan Atlanta, and Federally Qualified Health Centers were trained by Morehouse School of Medicine using the jointly developed competency-based curriculum.

In September 2009, the Georgia Society for Clinical Oncologists (GASCO) and Georgia CORE (Center for Oncology Research and Education) created the Cancer Patient Navigators of Georgia. This organization is inclusive of all cancer navigators, whether lay, nurse professionals, social work navigators, or others. The organization features a quarterly newsletter and an annual conference in conjunction with GASCO each year.
Since 2016, a multidisciplinary group has reinvigorated efforts from past years to plan strategies and establish the profession in Georgia. A steering committee of interested supporters convened to explore the feasibility of this plan. Following an initial CHW Forum in 2017 attended by 100 interested CHWs, supervisors, program directors, and insurance payers, public health professionals, academicians, and others from across the state, a Georgia CHW Advisory Group was formed. This Advisory Group has representatives from the health/medical industry, academia, CHWs, an advocacy group and others. The Advisory Group and Steering Committee engaged in an iterative process to develop consensus on standardized CHW training, credentialing, professional development, and Medicaid reimbursement for $\mathrm{CHWs}$. The $\mathrm{GaDPH}$ created a $\mathrm{CHW}$ Initiative Program to manage and communicate opportunities for $\mathrm{CHW}$ professional development and integration of the $\mathrm{CHW}$ workforce into healthcare practice and public health promotion throughout the state. In 2018, a Georgia CHW Coalition was formed to advocate for the formal recognition of the $\mathrm{CHW}$ workforce, and to promote its sustainability through third-party reimbursement for their services through the expansion of Medicaid.

\section{RESULTS}

The work of the Georgia CHW Steering Committee and CHW Advisory Group, and the Georgia CHW Coalition have resulted in three Community Health Worker Forums since 2016. The Forums have been attended by CHWs, CHW employers, and supporters from across the state of Georgia. Outcomes have included a Georgia $\mathrm{CHW}$ Consensus Report. The Consensus Report includes a definition of CHWs that is similar to that of the BLS and that of the APHA but was modified through a consensus-building process to be more representative of CHW practice in Georgia (Georgia CHW Consensus Report, 2017).

The Georgia definition of a $\mathrm{CHW}$ includes that a $\mathrm{CHW}$ is a frontline health worker who is a trusted member of and/or has a demonstrated working knowledge of the community and individuals served. As a part of this definition, it was noted that:

- This relationship enables the CHW to serve as a resource to promote, maintain and improve individual, family and community health.

- In partnership with health care providers and other human service agencies, CHWs provide person-centered support to individuals and families to help improve access to care, assist with navigating the health care and social service system, advocate for individual, family and community needs and build client capacity to increase health knowledge and self-sufficiency.

- This is achieved through a range of activities such as outreach, health screening, community 
education, individualized health coaching, monitoring and informal counseling. Informal counseling is defined as any situation where one person goes to another for advice and help and is not intended to replace professional therapy or counseling.

The Steering Committee and Advisory Group are comprised of approximately 30 individuals who have had some experience in working with $\mathrm{CHWs}$ and could contribute to creating a full landscape of CHWs and their value towards transforming the health of communities. They represent academia, health insurers including Medicaid, Federally Qualified Health Centers (FQHCs), community-based organizations, public health, social workers, physicians, CHWs, and the Georgia Health Policy Center consultants. In 2018, the GaDPH established a position for, and hired a CHW Program Manager.
The Forums allowed for opportunities to learn from successful experiences of national $\mathrm{CHW}$ programs and programs within the state. With skilled facilitators, we were able to include the input of Forum attendees into a Georgia CHW Consensus Plan. We reviewed literature and catalogued interventions and policy documents that can help to reduce our need to repeat missteps from other efforts.

The CHW Coalition for Georgia is being coordinated by Georgia Watch, the state's leading consumer advocacy organization. Georgia Watch is a nonprofit and nonpartisan organization founded in 2002 with a mission of equity and justice for all Georgia consumers (georgiawatch.org). Since 2017, the membership has grown to 80 stakeholders representing 40 different agencies, organizations, and individuals.

Table 1

Three examples of CHW Programs - Hospital \& ED utilization rates

\begin{tabular}{|c|c|c|}
\hline Program & Outcome & Cost Measure and Savings \\
\hline \multicolumn{3}{|c|}{ Community Outreach and Cardiovascular Health • Baltimore, MD (Bhaumik et al., 2013) } \\
\hline $\begin{array}{l}\text { ED visit diversion } \\
\text { Outreach and enrollment }\end{array}$ & $\begin{array}{l}\text { - Decrease in utilization and } \\
\text { payments in: ED, inpatient } \\
\text { service, non-narcotic and narcotic } \\
\text { prescriptions, outpatient primary } \\
\text { care services, and outpatient } \\
\text { specialty care services by patients }\end{array}$ & $\begin{array}{l}\text { Cost Measures: The difference in cost from 6-months } \\
\text { before to 6-months after CHW intervention was } \\
\text { calculated for: } \\
\text { (1) ED utilization/payment, (2) inpatient utilization and } \\
\text { payment, (3) prescription counts and payment, (4) } \\
\text { narcotic counts and payments, (5) PCP visits / payment, } \\
\text { (6) Specialist (non-PCP) visits and payment } \\
\text { Cost Savings: The total cost differential post-intervention } \\
\text { compared to pre-intervention: } \$ 2,044,465 \text {. }\end{array}$ \\
\hline \multicolumn{3}{|c|}{ Community Health Workers and Medicaid Managed Care in New Mexico (Johnson et al., 2012) } \\
\hline $\begin{array}{l}\text { ED visit diversion related to } \\
\text { diabetes management }\end{array}$ & $\begin{array}{l}\text { - } 38 \% \text { reduction in ED visits } \\
\text { - } 53 \% \text { reduction in ED admissions } \\
\text { - } 30 \% \text { reduction in total hospital } \\
\text { admissions }\end{array}$ & $\begin{array}{l}\text { Cost Measures: Medicaid reimbursement for charges } \\
\text { incurred for both inpatient and outpatient services, } \\
\text { excluding outpatient prescriptions } \\
\text { Cost Savings: Average savings of } \$ 2,245 \text { per patient per } \\
\text { year, a total savings of } \$ 262,080 \text { for } 117 \text { patients }\end{array}$ \\
\hline \multicolumn{3}{|c|}{ Boston Children's Hospital Community Asthma Initiative • Boston, MA (Allen et al., 2013) } \\
\hline Asthma management & $\begin{array}{l}\text { - Significant increase in caregiver } \\
\text { quality of life } \\
\text { - Decrease in symptom days } \\
\text { - } 17 \% \text { decline in urgent health } \\
\text { services use }\end{array}$ & $\begin{array}{l}\text { Cost Measures: The potential savings in urgent medical } \\
\text { care costs were estimated as the product of the number of } \\
\text { units of urgent care services multiplied by the unit cost of } \\
\text { each service } \\
\text { Cost Savings: Savings in urgent care cost for a } 2 \text {-month } \\
\text { period totaled } \$ 57-\$ 80 \text { per child }\end{array}$ \\
\hline
\end{tabular}

Note. Source: Adapted from Michigan CHW Alliance, 2020.

Programs across the country have contributed to a growing body of evidence to show the effectiveness of CHWs in the areas of system navigation, home-based support, case management and care coordination, and health promotion and coaching. Disease areas include cardiovascular diseases, cancers, asthma, mental health, and HIV. Some examples from the literature that include cost savings and reduced hospitalizations and ED utilization are in Tables 1 and 2.

\section{How CHWs make a difference and return on Investment}

A 10-year old program called IMPaCT based at the University of Pennsylvania has one of the better examples of sustainability combined with cost-effectiveness. They conducted a randomized control study of CHWs versus usual care and found that for every dollar invested in the 
intervention $\$ 2.47$ would return to an average Medicaid payer within the fiscal year. They used an investment analysis that is based on a randomized controlled trial. IMPaCT is a standardized community health worker intervention in Philadelphia that addresses unmet social needs for disadvantaged patients (Kangovi et al., 2020).
More examples of CHW programs that have demonstrated significant Return on Investment (ROI) appear in Table 2.

Table 2

CHW Programs - total cost per member of the population per month and return on Investment

\begin{tabular}{|c|c|c|}
\hline Health Issue & Outcomes & Cost Measures \& Savings \\
\hline \multicolumn{3}{|c|}{$\begin{array}{l}\text { The Arkansas Community Connector Program - Monroe, Lee, and Phillips Counties } \\
\text { (Felix et al., 2011) }\end{array}$} \\
\hline $\begin{array}{l}\text { Outreach and } \\
\text { community-based long-term } \\
\text { care services }\end{array}$ & $\begin{array}{l}\text { Statistically significant negative } \\
\text { effect on growth in Medicaid } \\
\text { spending over a 3- year period } \\
\text { Average growth in Medicaid } \\
\text { spending was } 23.8 \% \text { lower for } \\
\text { program participants }\end{array}$ & $\begin{array}{l}\text { Cost Measures: Annual measures for use of Medicaid } \\
\text { services and spending for inpatient and outpatient } \\
\text { medical services, nursing home services, home and } \\
\text { community-based services } \\
\text { Cost Savings: } \$ 3.515 \text { million estimated savings in } \\
\text { Medicaid expenditure for } 919 \text { program participants in } \\
3 \text { years. } \$ 2.619 \text { million in net savings. } \\
\text { ROI: } \$ 2.92 \text { per dollar invested in program }\end{array}$ \\
\hline \multicolumn{3}{|c|}{ Denver Health Community Voices, Community Voices (Whitley et al., 2006) } \\
\hline Outreach and enrollment & $\begin{array}{l}\text { - Increase in primary \& specialty care } \\
\text { visits } \\
\text { - Decreased urgent care, inpatient \& } \\
\text { outpatient behavioral health visits }\end{array}$ & $\begin{array}{l}\text { Cost Measures: Charge data for utilization, charges, } \\
\text { reimbursements, and payer sources for services } \\
\text { utilized by CHW clients. Cost-to-charge ratio of } 62 \% \\
\text { applied to final ROI calculation } \\
\text { Cost Savings: Monthly uncompensated costs reduced } \\
\text { by } \$ 14,244 \text {. Program costs were } \$ 6,299 \text { per month. } \\
\text { ROI: } \$ 2.28 \text { per dollar invested. } \$ 95,941 \text { saved } \\
\text { annually }\end{array}$ \\
\hline \multicolumn{3}{|c|}{ Sinai Pediatrics Asthma Intervention, Chicago, IL (Margellos-Anast et al., 2012) } \\
\hline Asthma management & $\begin{array}{l}\text { - } 35 \% \text { reduction in asthma symptoms } \\
\text { - } \\
\text { - } 75 \% \text { reduction in urgent health } \\
\text { resource utilization } \\
\text { - Increased enrollment in medical } \\
\text { management }\end{array}$ & $\begin{array}{l}\text { Cost Measures: Cost savings analysis } \\
\text { Cost Savings: } \$ 2,561.60 \text { per participant. } \\
\text { ROI: } \$ 5.58 \text { per dollar spent on intervention }\end{array}$ \\
\hline
\end{tabular}

Note. Source: Adapted from Michigan CHW Alliance, 2020.

\section{The importance of CHWs in Georgia}

Heart disease, stroke, cancer, diabetes, and chronic respiratory disease are some of the leading causes of death in Georgia, and most of the deaths are preventable, according to GaDPH (2016). Approximately 71\% of premature deaths in Georgia are attributed to poor diet and physical inactivity (32\%) and to tobacco use (39\%) (GaDPH, 2016). Since the 1990s, we have had CHWs programs successfully responding to chronic diseases in research and demonstration projects. Table 3 features a sampling of Georgia's CHW programs.

There is much expertise in the state of Georgia in developing, implementing, and evaluating CHW programs. Kaiser Permanente partnered with the United Way of Greater Atlanta to reduce the number of ED visits at Grady Memorial Hospital. In this program, CHWs helped to navigate patients from the ED to a newly created primary care clinic a few yards from the ED. Community Voices has created and managed $\mathrm{CHW}$ programs across the country and been instrumental in helping to develop $\mathrm{CHW}$ policy in many locations. With Atlanta programs including the Westside Collaborative and Choice Neighborhoods, CHWs are working with the Atlanta Housing Authority and employment agencies to connect residents with a permanent source of medical care. There is an innovative program at Morehouse School of Medicine that recruits and trains High School students as CHWs (HSCHW). Launched in 2016, this program has trained $77 \mathrm{CHWs}$ who can be health promoters in their families, communities and schools. The $\mathrm{HSCHW}$ program can also serve as a pipeline for the $\mathrm{CHW}$ profession, and other health professions as participants gain more exposure to those professions during training. Georgia FQHCs have a strong history with employing CHWs to improve patient compliance and to help control chronic diseases. We need to build on those examples and make this a permanent integrated workforce. We can build on the experiences, lessons learned, and the foundation that these stakeholders have built for $\mathrm{CHW}$ practice and policy in Georgia. 
Table 3

Sample Research and Demonstration Projects in Georgia

\begin{tabular}{l}
\hline Disease Area \\
\hline Asthma: \\
In 2017, there were 2,614 asthma related hospitalizations among \\
children 0-17 years of age in Georgia. The total cost of \\
asthma-related hospitalizations among Georgia children \\
amounted to \$37.4 million (https://dph.georgia.gov/Asthma).
\end{tabular}

Cancers:

Over 36,500 cases of cancer are diagnosed annually, and Georgia's lung and prostate cancer incidence and death rates are above national averages.

In 2005 , cancer cost the state $\$ 4.6$ billion. This figure includes: $\$ 1.7$ billion in direct medical costs, $\$ 406$ million in indirect morbidity costs, and $\$ 2.5$ billion in indirect mortality costs. Many of the cancers are preventable and are attributed to tobacco use, poor diet and physical activity.

(GCCREvaluationReport.pdf).

Based on CDC estimates in 2010, the overall medical care expenditure for cancer in Georgia is $\$ 3.7$ billion, additionally CDC estimates that Georgia patients miss more than one million days of work due to cancer, an estimate of more than $\$ 243$ million in lost productivity (Bayakly, 2016).

CHWs/Navigators

Zap Asthma was among the first CHW programs in Georgia. A public-private partnership, they recruited, trained, and employed CHWs to conduct home assessments with families of asthmatic patients; collaborated with agencies and organizations to reduce asthma triggers in the home, like mold, mildew, and insects. (ORC Macro, 2000)

Breast and Cervical Cancer Screening Program (BCCP) was a partnership among the GaDPH, American Cancer Society, the United Way, Grady Memorial Hospital, and Georgia CORE. Navigators were hired to conduct education and to increase early detection among low-income women.

Cancer Centers of Excellence - in five regions across the state CHWs collaborated with community agencies and organizations to provide cancer education and/or to increase screening in breast, cervical, colorectal and prostate cancers.

Avon Comprehensive Breast Health Program - Hired CHWs and client Navigators to provide education and increase screenings and to provide support for patients after diagnosis at Grady Hospital. Program was funded for 15 years. (Gabram \& Jacob-Arriola, 2009)

Cancer Navigators of Rome, GA. The only free-standing building in Georgia for Navigators/CHWs. They receive direct referrals of recently diagnosed breast cancer patients to help them navigate through their treatment journey. The program is more than 10 years old. Some 87 percent of patients in Harbin's Integrative Oncology Program work with Cancer Navigators.

Cardiovascular Diseases/Cardiometabolic Syndrome: CVD is the single leading cause of death in Georgia, accounting for more than 20,000 deaths a year -- about 1 in 3 deaths overall. Most of these deaths are premature and preventable. In 2012, the average charge per heart disease hospitalization in Georgia was $\$ 45,700$. Total hospital charges for heart disease in Georgia were $\$ 4.2$ billion accounted for $68 \%$ of all CVD hospital charges (\$6.1 billion). https://dph.georgia.gov/heart-disease

\section{E-healthy Strides. A self - monitoring program using technology with CHWs as coaches. Morehouse School of Medicine and City of Atlanta employees.}

Patient-centered Medical Homes and CHWs. A pilot research program funded by United Health Foundation. Patients were high-risk for CVD. CHWs made home visits and were able to increase compliance and reduce hospitalizations over the duration of the one-year research project.

REACH Program (Racial and Ethnic Approaches to Community Health). A CDC funded program conducted locally and nationally. The Program encourages community-based collaborations and partnerships to increase health equity.

\section{Diabetes:}

Georgia's death rate for diabetes is $8 \%$ higher than the national average. As of 2013 the total cost of diabetes in Georgia is approximately $\$ 5.1$ billion. Of that, $\$ 3.3$ billion was attributed to direct medical cost and the remaining $\$ 1.8$ billion was attributed to loss of productivity and sick days. - Diabetes hospitalizations from Georgia's Medicaid and State Health Benefit Plan populations resulted in charges of $\$ 30$ million in 2013 for just 36,567 admissions

\section{Chronic Diseases:}

Some programs focused on one chronic disease condition. Others addressed multiple chronic diseases with common risk factors, e.g., tobacco, nutrition, and exercise

\section{Chronic Care Clinic:}

Created to lower Grady's emergency room costs by diverting some of its most frequent ER visitors into a specialized clinic (Hart, 2017)

In addition to the programs above to address chronic diseases, there were some that addressed only diabetes.

iAdapt Program and iAdapt 2.0. Trained over $30 \mathrm{CHWs}$ to work with patients from an FQHC in Type 2 diabetes control. The iAdapt 2.0 project expanded to more community-based education and control.

Choose Health - CHWs based at $5 \mathrm{FQHCs}$ and one hospital to reduce ED visits and return visits for hospitalizations. Collaboration with United Way of Greater Atlanta.

At Grady Memorial Hospital, CHWs help patients who are ED

"frequent flyers" to navigate the healthcare and social systems. \$2 million grant in 2017 saved $44 \%$ of what patients would have cost the system. There are plans to replicate parts of the program in rural GA communities. (Hart, 2019) 
Table 4

Potential benefits to a variety of stakeholders

\begin{tabular}{|c|c|}
\hline $\begin{array}{l}\text { Individuals -including patients and caregivers } \\
\text { Improved patient satisfaction } \\
\text { Improved patient-doctor communication } \\
\text { Better quality of life } \\
\text { Lower out-of-pocket costs } \\
\text { Fewer missed workdays }\end{array}$ & $\begin{array}{l}\text { Providers } \\
\text { Improved patient-doctor/provider communication } \\
\text { * Better patient outcomes } \\
\text { Meet quality targets }\end{array}$ \\
\hline $\begin{array}{l}\text { Payers/Business and Industry } \\
\text { Improved quality scores } \\
\text { Positive ROI }\end{array}$ & $\begin{array}{l}\text { Society/Population } \\
\text { Lower health care costs } \\
\text { Increased work productivity and school attendance } \\
\text { CHW jobs created } \\
\text { Improved model for meeting physician/nurse shortage } \\
\text { Address determinants of health beyond the medical and genetic - i.e., social and } \\
\text { behavioral determinants } \\
\text { Improved individual and community health }\end{array}$ \\
\hline
\end{tabular}

Most states have some level of CHW programs. In moving from action or knowledge to policy, 15 states have enacted legislation to establish CHW scope of practice, 6 have enacted laws that authorize a certification process, and 5 of the states with certification processes authorize the creation of standardized curricula on the basis of core competencies and skills training (Fulmer et al., 2020). Minnesota, and more recently South Dakota, are the only states that allow Medicaid payments for credentialed CHWs (Association of State and Territorial Health Officials, 2017) (Hynes, 2020).

\section{DISCUSSION}

It is clear that something is missing in our U.S. healthcare system because we spend a higher share of our economy on healthcare when compared with 10 of the highest-income countries (United Kingdom, Canada, Germany, Australia, Japan, Sweden, France, the Netherlands, Switzerland, and Denmark). Yet we have a lower life expectancy, a higher infant mortality, and a and higher suicide rate than those 10 countries (Papanicolas et al., 2018). In 2018, our national healthcare expenditures grew by $4.6 \%$ to $\$ 3.6$ trillion or about $18 \%$ of our gross national product (Health Affairs, 2019). Businesses, payers, and residents are seeking ways to slow these rising costs. The full recognition of the $\mathrm{CHW}$ workforce is one proven response.

Georgia is positioned to have some of the most improved healthcare systems in the country. Georgia can already boast of nationally respected hospitals, four medical schools, and other top health programs, including $\mathrm{CHW}$ programs, yet ranks in the bottom one-third of states for the health outcomes of its residents, such as premature deaths, maternal and infant mortality and diabetes (AHR, 2019). We have CHW programs that have demonstrated effectiveness and cost effectiveness (Table 1 and Table 2) in reducing barriers to care, improving healthcare access, and addressing SDoH (AJC, 2019). The business community would justifiably question whether $\mathrm{CHW}$ interventions save money, in addition to improving the patient experience when encountering the medical care system and saving lives. The response is a resounding yes, as shown by many studies across the country (Tables 1 and 2). We have the capacity to make our system work better for millions of Georgians who find our current healthcare system is not accessible, affordable, or available to them. Whether because of lack of insurance, the lack of healthcare providers or facilities, or mistrust of the medical care system, many Georgians suffer being marginalized getting medical care -- both physical health (cancers, hypertension, asthma, preventable maternal mortality), and mental and behavioral health. We can and must do better. We must be willing to acknowledge, accept, and act upon the knowledge that contributors to disease, disability, and death are just 10-20 percent medical and genetics (RWJF, 2011). The remaining 80 percent is from $\mathrm{SDoH}$ - environmental and lifestyle-related. Because all the causes of mortality are not clinical, the solution should include non-clinical interventions. CHWs should be an integral part of the interdisciplinary team that develops a patient's health plan, especially for economically disadvantaged populations. We have to do a better job of communicating the successes of CHWs in improving health outcomes to stakeholders, including business and industry, physicians, social workers, policymakers, and the general public to expand knowledge of the value of CHWs and to gain support for CHWs and their collaborations with individuals, families, and communities in improving healthcare overall and advancing health equity. There are simple things we can do within our existing systems to bridge gaps - one being to require all medical clinics to inquire on intake forms about possible $\mathrm{SDoH}$. The questions should be more specific than whether the patient needs the services of a social worker. Many patients may be embarrassed or not know what services a social worker or a CHW can provide. The Social Worker and $\mathrm{CHW}$ can work together to identify local resources to 
remove barriers. The CHW can work more closely with the client to be sure patients connect with the resources and to help them build on their own social support systems to achieve better health. After all, one of the roles of CHWs is to build individual and community capacity. The goal is to increase self-sufficiency and self-efficacy in patients to partner in improving their own health. CHWs can be an asset in achieving the Triple Aim as defined by the Institute for Health care Improvement: Improving Population Health, Improving Patient Experiences and Outcomes, and Reducing Healthcare costs (Institute for Healthcare Improvement, 2015).

National support for the workforce is evidenced by the expected growth of the workforce (BLS, 2017). According to a report on Allied Health Professions, the demand in the CHW workforce is expected to grow in service coordination from $6-18 \%$ depending on the area they serve. Projections showed an increase in demand for CHWs whose work is with Patient-Centered Medical Homes (PCMH) with high social need $(18 \%)$, those in rural communities $(13 \%)$, and children with special-needs like sickle-cell (6\%) (BLS, 2017). This report informs the current need for recruitment and training the $\mathrm{CHW}$ workforce, so they are prepared to serve in the future. Medicaid has recognized SDoH as barriers to health and has developed guidelines for policymakers on reimbursement of these nonmedical expenses (RWJF, 2019). We should make further study of these reports to determine how to meet the unique needs for the diverse population of Georgia. We should look at the numbers and determine how we can do the best job at reducing unnecessary disease, disability, death and their concomitant economic costs and human suffering. As Georgia looks towards its own version of Medicaid expansion, we must push to include the CHW workforce in every domain that will improve the individual and community health of Georgians.

\section{Unanticipated benefits of $\mathrm{CHWS}$}

The novel coronavirus (COVID-19) pandemic highlighted many weaknesses in our healthcare system. It also provided many unexpected opportunities for the medical profession. The acceleration of the use of telemedicine and insurance approvals for its implementation for both urban and rural areas was much unexpected, for example. The discipline of CHWs also provided some revelations for opportunities in public health. During major health crises such as disasters and pandemics such as COVID-19, CHWs can offer a unique and valuable asset. As an existing trusted health resource often residing in the communities they serve, they can help to distinguish facts from misinformation, deliver timely recommendations to underserved and disenfranchised communities, and serve as effective contact tracers because they are already established and respected health workers in many communities. CHW's can be the bridge between communities at greatest risk and the various public health agencies responsible for managing the crisis/pandemic at hand. Key is a CHW's ability to receive and communicate accurate health information, provide basic care instructions (e.g.. minimizing social contact, frequent handwashing), and already have demonstrated competencies and transferable skills in more than 10 areas, including communication skills and ethical issues. Working with the healthcare system, CHWs are in place help navigate those persons who are newly in need of medical services through the system so they are not lost to receiving care they might need.

They can serve to facilitate connections of communities to services to address mental health needs, financial, food services, and with medical services for those who are not already connected with primary care doctors and who might have feared going to EDs for fear of contracting the virus. CHWs proved to be an unplanned asset in the aftermath of Hurricane Katrina in New Orleans, LA in 2015. CHWs, their skills, and their knowledge of the people and these communities at highest risk of suffering from the tragedy, were an invaluable resource in the recovery process both long-term and short-term (Wennerstrom et al.,2011).

\section{IMPLICATIONS FOR PUBLIC HEALTH}

Persistent disparities in disease conditions in populations (Artiga et al., 2020; US-DHHS, 2011) have inspired us to examine more closely $\mathrm{SDoH}$ as a means of achieving health equity and at CHWs as the profession to deliver those services. CHWs are on the frontline as health workers (APHA, 2020) who have earned the trust of communities they serve to improve health, increase knowledge, connect existing resources, identify and remove barriers to care, and increase the capacity of individuals, families, and communities to be true partners in improving their health.

In addition to CHW programs, or as enhancements to $\mathrm{CHW}$ programs, there are many creative interventions across the country to improve health with a focus on those contributors to health that are beyond the medical and genetics but are within our grasp to make the changes. Medicaid has a larger focus on health outcomes versus the volume of patients seen (RWJF, 2019). Two examples of innovations in medical environments to address the health needs of the patient include: 1. Providing supportive housing to a seriously mentally ill person who otherwise would be homeless can significantly reduce medical expenditures on emergency department visits and inpatient care and 2. Connecting low-income older adults with chronic conditions to the Supplemental Nutrition Assistance Program or providing home meal delivery can reduce health care costs and utilization (RWJF, 2019). Another innovation includes the many clinics and hospitals that have established "Food Pharmacies" and write prescriptions for seniors, and other patients for whom there may be issues of chronic hunger exacerbating the basic health issue (Tobin, et al., 2020).

Creating policy to support the profession of CHWs, credentialing CHWs, and sustaining CHWs will create a 
system that will advance health equity for Georgia's populations. In addition to being instrumental in primary, secondary, and tertiary prevention across the health continuum, CHWs can be in place for unforeseen emergencies like the COVID-19 pandemic or Hurricane Katrina. CHWs should continue to serve in their usual defined public health roles including, but not limited to monitoring and solving community health problems, investigating health issues, informing and educating, and mobilizing partnerships to improve health. We must, however, continue to use the research and resources at hand to develop innovations that can strengthen the use of CHWs to reduce the impact of uncontrolled chronic diseases on our state and ways to support their role as connectors between medical and social services to prevent gaps in patient support.

We have a responsibility in our roles of public health practitioners and stakeholders to conduct research and translate the best evidence-based research to practice that will transform the health of individuals and communities. We have the evidence for CHWs. With the support of its academic and medical institutions, healthcare payers, and other stakeholders, Georgia has an opportunity to build on the work of the past four years and the Georgia CHW Coalition to create one of the best and most improved systems for healthcare in the country that is focused on improved health outcomes and demonstrated positive return on investment. We must make bold moves to reduce gaps in services that lead to excess morbidity and mortality in our state from maternal and child health, asthma, and other chronic diseases like hypertension and diabetes. Together, we can formally establish the $\mathrm{CHW}$ profession in Georgia with sustainability of the workforce through an expansion of Medicaid.

\footnotetext{
Acknowledgements

Research reported in this publication was supported in part by the National Center for Advancing Translational Sciences of the National Institutes of Health under the Georgia Clinical and Translational Science Alliance Award UL1TR000454.
}

\section{References}

Agency for Healthcare Research and Quality. (June 2019). Impact of community health worker certification on workforce and service delivery for asthma and other selected chronic diseases. U.S. Department of Health and Human Services.

Albritton, E. (2016). How states can fund community health workers through Medicaid to improve people's health, decrease costs, and reduce disparities. Families USA - The Voice for health care consumers. Accessed on February 15, 2020. https://familiesusa.org/resources/how-states-can-fund-communit y-health-workers-through-medicaid-to-improve-peoples-healthdecrease-costs-and-reduce-disparities/

Allen J.K., Dennison Himmelfarb C.R., Szanton S.L., \& Frink K.D. (2013). Cost-effectiveness of nurse practitioner/community health worker care to reduce cardiovascular health disparities. Journal of Cardiovascular Nursing; 00(0); 1-7.

America's Health Rankings. (2019). Analysis of America's health rankings composite measure. United Health Foundation, AmericasHealthRankings.org, Accessed May 27, 2020. https://www.americashealthrankings.org/explore/annual/measur e/Overall/state/GA

America's Health Rankings. (2019). Analysis of CDC WONDER Online Database, Underlying cause of death, multiple cause of death files. United Health Foundation. Accessed May 27, 2020. AmericasHealthRankings.org

America's Health Rankings analysis of CDC WONDER Online Database, Mortality files, United Health Foundation, AmericasHealthRankings.org, Accessed February 20, 2020. https://www.americashealthrankings.org/explore/health-of-wom en-and-children/measure/maternal_mortality_a/state/GA?edition -year $=2019$

American Public Health Association. Accessed February 21, 2020. https://www.apha.org/aphacommunities/member-sections/comm unity-health-workers

APM Research Lab (American Public Media). (June 9, 2020). The Color of coronavirus: COVID-19 deaths by race and ethnicity, Accessed June 9, 2020.

https://www.apmresearchlab.org/covid/deaths-by-race

Artiga, S., Orgera, K., \& Pham, O. (March 2020). Disparities in health and health Care: Five key questions and answers. Kaiser Family Foundation.

Association of State and Territorial Health Officials. (Updated 2017). Community health workers_Training/certification standards: current status. Accessed February, 24.2020.

Barnett, M.L., Gonzalez, A. Miranda, J., Chavira, D.A., and Anna S. Lau, A.S. (2018). Mobilizing community health workers to address mental health disparities for underserved populations: A systematic review. Adm Policy Ment Health. 45(2): 195-211. Accessed May 27, 2020. doi: 10.1007/s10488-017-0815-0

Bayakly, A. Rana, (2015). Burden of chronic disease in Georgia. Georgia Department of Public Health. Accessed January 20, 2020. http://dph.georgia.gov/

Bhaumik U, Norris, K, Charron, G, Walker, S.P., Sommer, S.J., Chan, E. Dickerson, D.U., Nethersole, S., \& Woods, E.R. (2013). A cost analysis for a community-based case management intervention program for pediatric asthma. Journal of Asthma; 50(3): 310-317.

Brownstein JN, Hirsch GR, Rosenthal EL, Rush C. (2011). Community health workers " 101 " for primary care providers and other stakeholders in health care systems. J Ambulatory Care Management. 34(3):210-220.

Bureau of Labor Statistics. (2017, May). U.S. Department of Labor. Accessed January 17, 2020. https://www.bls.gov/oes/2017/may/oes211094.htm.

Bureau of Labor Statistics. Standard Occupational Classification. Community Health Workers. (2010). U.S. Department of Labor. Accessed May 27, 2020. http://www.bls.gov/soc/2010/soc211094.htm.

Campbell, JD, Brooks, M, Hosokawa, P, Robinson, J, Song, L, and Krieger, J. (November 2015). Community health worker home visits for medicaid-enrolled children with asthma: Effects on asthma outcomes and costs. Am J Public Health. 105(11): 2366-2372. doi: 10.2105/AJPH.2015.302685

Centers for Disease Control and Prevention, Division for Heart Disease and Stroke Prevention. (December 2016). State law fact sheet: a summary of state community health worker laws. Accessed July 12, 2019.

https://www.cdc.gov/dhdsp/pubs/docs/SLFS-Summary-State-C HW-Laws.pdf

Centers for Disease Control and Prevention (CDC). (2016). Promoting policy and systems change to expand employment of community health workers. Available at: http://www.cdc.gov/dhdsp/pubs/chw_elearning.htm.

Centers for Disease Control and Prevention, Division for Heart Disease and Stroke Prevention. (2017). What evidence supports 
state laws to establish community health worker scope of practice and certification?

https://www.cdc.gov/dhdsp/pubs/docs/CHW-PEAR.pdf. Accessed July 12, 2019.

Centers for Disease Control and Prevention. (2017). CDC WONDER. Accessed on May 31, 2017. Available at: http://wonder.cdc.gov/ucd-icd10.html.

Centers for Disease Control and Prevention. The National Center for HIV/AIDS, Viral Hepatitis, STD, and TB Prevention (NCHHSTP). Social determinants of health. Accessed on February 15, 2020.

https://www.cdc.gov/nchhstp/socialdeterminants/faq.html

Centers for Disease Control and Prevention. Social determinants of health. Accessed May 27, 2020.

https://www.cdc.gov/socialdeterminants/index.htm

Centers for Disease Control and Prevention. Division of Heart Disease and Stroke. Community health workers: E-learning. U.S Department of Health and Human Services. Accessed February 24, 2020. https://www.cdc.gov/dhdsp/chw_elearning/s1_p9.html Centers for Disease Control and Prevention. Division of Heart Disease and Stroke Prevention. (2015). A Community health worker training resource. U.S. Department of Health and Human Services.

https://www.cdc.gov/dhdsp/programs/spha/chw_training/index.h tm

Centers for Disease Control and Prevention. (April 2015).

Addressing chronic disease through community health workers. A policy and systems- level approach. A policy brief on Community Health Workers. U.S. Department of Health and Human Services.

https://www.cdc.gov/dhdsp/docs/chw_brief.pdf

Centers for Disease Control and Prevention. Integrating community health workers on clinical care teams and in the community. U.S. Department of Health and Human Services. Accessed February 24, 2020.

https://www.cdc.gov/dhdsp/pubs/docs/Best_Practice_Guide_CH W_508.pdf

Families USA Community health worker sustainability collaborative. Accessed February 27, 2020.

https://familiesusa.org/our-work/c-h-w/

Felix, H.C., Mays, G.P., Stewart, M.K., Cottoms, N., \& Olson, M. (2011). Medicaid savings resulted when community health workers matched those with needs to home and community care. Health Affairs; 30(7): 1366-1374.

Fulmer, E.B., Barbero, C., Gilchrist, S., Shantharam, S. S., Bhuiya, A. R., Taylor, L.N., Jones, C. D. (March/April 2020).

Translating workforce development policy interventions for community health workers: Application of a Policy Research Continuum. Journal of Public Health Management and Practice. Volume 26 - Issue - p S10-S18.

doi: 10.1097/PHH.000000000000112. https://journals.lww.com/jphmp/Fulltext/2020/03001/Translatin g_Workforce_Development_Policy.3.aspx

Gabram, S.G.A. and Jacob-Arriola, K.R. (2009). The AVON foundation comprehensive breast center at Grady: Clinical, research and navigation successes. Accessed June 12, 2020. https://www.gasco.us/documentz/gasconavigation072609.pdf

Georgia Comprehensive Cancer Report and Evaluation. (2016). GCCREvaluationReport.pdf Georgia Department of Public Health. State health assessment. Leading causes of premature death. P 27.

Georgia Community Health Worker Consensus Report. (2017).

Georgia Department of Public Health (not published).

Georgia Watch. Website. Accessed May 28, 2020.

https://georgiawatch.org/about/
Hart, A. (2019, May). Kemp could model Georgia Medicaid waiver off Grady program. The Atlanta Journal-Constitution. Accessed May 27, 2020.

https://www.ajc.com/news/state--regional-govt--politics/kemp-c ould-model-georgia-medicaid-waiver-off-grady-program/z2s4nq Y8H2ktnvviYk1OxJ/

Hart, A. (September 6, 2019). The fragile state of Georgia healthcare. AJC. Accessed May 27, 2020.

https://www.ajc.com/news/state--regional-govt--politics/the-frag ile-state-georgia-health-care/4jbCqqLx3lvmh89szIjsII/

Hartman, M, Martin, A.B., Benson, J., Catlin, A. (December 2019). National health care spending in 2018: Growth driven by accelerations in medicare and private insurance spending. Health Affairs. VOL. 39, NO. 1.

Health Resources and Services Administration. (2007). Community Health Workers National Workforce Study. Rockville (MD): U.S. Department of Health and Human Services. Available from: http://bhpr.hrsa.gov/healthworkforce/chw/default.htm\#preface Google Scholar

Health Resources and Services Administration. Allied health workforce projections, 2016-2030: Community health workers. U.S. Department of Health and Human Services. Accessed 2.21.2020.

https://bhw.hrsa.gov/sites/default/files/bhw/nchwa/projections/c ommunityhealth-workers-2016-2030.pdf

Hernandez-Cancio, S. \& Albritton, E. (2017). Unleashing the power of community health workers: The CHW sustainability collaborative. Families USA.

https://familiesusa.org/resources/unleashing-the-power-of-commun ity-healthworkers-the-chw-sustainability-collaborative/.

Accessed February 24, 2020.

Hynes, S. (January 29, 2020). A Blueprint for success: Medicaid reimbursement for community health worker services in South Dakota. Webinar PowerPoint.

https://doh.sd.gov/documents/diseases/chronic/BlueprintforSucc ess_WebinarSlides.pdf Accessed January 29, 2020.

IHI Triple Aim Measures. Institute for Healthcare Improvement. (2015). Accessed May 27, 2020.

http://www.ihi.org/Engage/Initiatives/TripleAim/Pages/Measure sResults.aspx

Institute of Medicine. (2010). A population-based policy and systems change approach to prevent and control hypertension.

http://www.nationalacademies.org/hmd/ /media/Files/Report $\% 20 \mathrm{~F}$ iles/2010/APopulation-Based-Policy-and-Systems-Change-Appr oach-to-Prevent-and-Control-

Hypertension/Reduce\%20and\%20Control\%20Hypertension \%2020 10\%20\%20Report\% 20Brief.ashx

Johnson, D., Saavedra, P., Sun, E., Stageman, A., Grovet, D., Alfero, C., Maynes, C., Skipper, B., Powell, W., \& Kaufman, A. (2012). Community health workers and medicaid managed care in New Mexico. Journal of Community Health; 37: 563-571.

Kangovi, S., Mitra, N., Grande, D.,White, M.L., McCollum, S., Sellman, J., Shannon, R.P., \& Long, J.A. . (2014).

Patient-centered community health worker intervention to improve posthospital outcomes: a randomized clinical trial. JAMA Intern Med;174(4):535-43.

Kangovi, S., Grande, D., \& Trinh-Shevrin, C. (2015). From rhetoric to reality - community health workers in postreform U.S. health care. N Engl J Med. 372(24):2277-9.

Kangovi, S., Mitra, N., Grande, D., Long, J.A., Asch, D.A. (2020). Evidence-based community health worker program addresses unmet social needs and generates positive return on investment. Health Affairs. 
https://www.healthaffairs.org/doi/full/10.1377/hlthaff.2019.0098 1. Accessed February 21, 2020.

Lee, B.Y. (September 10, 2016). Time to change the 15-minute limit for doctor visits. Accessed May 28, 2020.

https://www.forbes.com/sites/brucelee/2016/09/10/time-to-chan ge-the-15-minute-limit-for-doctor-visits/\#47f8d3c3477e

Margellos-Anast, H., Gutierrez, M.A., \& Whitman, S. (2012). Improving asthma management among African American children via a community health worker model: Findings from a Chicago-based pilot intervention. Journal of Asthma; 49(4): 380-389.

Michigan Community Health Worker Alliance (MiCHWA). CHWs and the Triple Aim. Accessed February 10, 2020.

https://www.michwa.org/wp-content/uploads/MiCHWA_CHW-R OI.pdf .

McCloskey, J. (2009). Promotores as partners in a community-based diabetes intervention program targeting Hispanics. Family \& Community Health, 32(1), 48-57.

National Academy for State Health Policy. State community health worker models. Accessed April 28, 2020.

https://nashp.org/state-community-health-worker-models/

National Association of Chronic Disease Directors (2009). A

Practical guide to ROI analysis. Accessed on May 31, 2017. Available at:

http://c.ymcdn.com/sites/www.chronicdisease.org/resource/resm gr/services/roi-1.pdf.

NEJM Catalyst. (2017). Healthcare innovations. Brief Article. What is value-based healthcare? https://catalyst.nejm.org/doi/full/10.1056/CAT.17.0558. Accessed February 28, 2020.

Nicholls, K., Picou, J., Curtis, J., \& Lowman, J. (2015). The Utility of community health workers in disaster preparedness, recovery, and resiliency. Journal of Applied Social Science, 9(2), 191-202. Retrieved May 30, 2020, from www.jstor.org/stable/26370925

ORC Macro. (2000). Evaluation of the ZAP asthma project contract: 200-96-0598, Task 14 Final Report. Accessed June 12, 2000. https://www.cdc.gov/ASTHMA/pdfs/zapasthma.pdf

Papanicolas, I., Woskie, L.R., \& Jah, A.K. (March 13, 2018). Health care spending in the United States and other high-income countries. JAMA. 2018;319(10):1024-1039. doi:10.1001/jama.2018.1150

Patient Protection and Affordable Care Act of 2010. Public Law 111-148. sections. 5101, 5102, 5313, 5403, and 3509.

Robert Wood Johnson Foundation. Life expectancy: Does where you live determine how long you live? Accessed February 10, 2020.

https://www.rwjf.org/en/library/interactives/whereyouliveaffects howlongyoulive.html

Robert W. Johnson Foundation. (December 7, 2011). Health care's blind Side: Unmet social needs leading to worse health.

Accessed May 27, 2020.

https://www.rwjf.org/en/library/articles-and-news/2011/12/healt h-cares-blind-side-unmet-social-needs-leading-to-worse-heal.ht $\mathrm{ml}$

Robert Wood Johnson Foundation. (February 1, 2019). Medicaid's role in addressing social determinants of health. Accessed May 17, 2020.

https://www.rwjf.org/en/library/research/2019/02/medicaid-s-rol e-in-addressing-social-determinants-of-health.html

Roland K.B., Milliken, E.L., Rohan, E.A., DeGroff, A., White, S., Melillo, S., Rorie, W.E.., Signes, C.C., \& Young, P.A. (2017). Use of community health workers and patient navigators to improve cancer outcomes among patients served by federally qualified health centers: a Systematic literature review. Health Equity.;1(1): 61-76.
Rosenthal, E.L., Wiggins, N., Brownstein, J.N., Johnson, S., Borbon, I.A., Rael, R. (1998). Final report of the national community health advisor study: Weaving the future. University of Arizona.

http://crh.arizona.edu/publications/studies-reports/cha

Rosenthal, E.L., Brownstein, N.J., Rush, C.H., Hirsch, G.R., Willaert, A.M., Holderby, L.R., \& Fox, D.J. (2010). Community health workers: Part of the solution. Health Affairs, Vol 29, No. 7. Accessed February 21. 2020. https://www.healthaffairs.org/doi/full/10.1377/hlthaff.2010.0081 ..

Rural Health Information Hub. Training approaches_state certification programs. Accessed February 10, $20 \overline{2} 0$.

ihttps://www.ruralhealthinfo.org/toolkits/community-health-wor kers/3/certification.

Rush, C. (2012). Return on investment from employment of community health workers. Journal of Ambulatory Care Management, 35(2), 133-137.

Satterfield, D., Burd, C., Valdez, L., Hosey, G. \& Shield, J.E. (2002). The "In-Between People": Participation of community health representatives in diabetes prevention and care in American Indian and Alaska Native communities. Health Promotion Practice. 203: 166 DOI:

10.1177/152483990200300212. Accessed February 26, 2020.

http://hpp.sagepub.com/content/3/2/166

Shah, M.K., Heisler, M., \& Davis, M.M. (February 2014). Community health workers and the patient protection and affordable care act: An opportunity for a research, advocacy, and policy agenda. J Health Care Poor Underserved. 25(1): (117-24.

Sung, J.F., Coates, R.J., Williams, J.E., Liff, J.M., Greenberg, R.S., McGrady, G.A., Avery, B.Y., \& Blumenthal, D.S. 1992. Cancer screening intervention among black women in inner-city Atlanta--design of a study. Public Health Rep. 107(4): 381-388.

Sung, J.F., Blumenthal, D.S., Coates, R.J., Williams, J.E., Alema-Mensah, E., Liff, J.M. (1997). Effect of a cancer screening intervention conducted by lay health workers among inner-city women. Am J Prev Med. 13(1):51-7.

Sung, J.F., Blumenthal, D.S., Coates, R.J., and Alema-Mensah, E. (1997). Knowledge, beliefs, attitudes, and cancer screening among inner-city African American women. J Natl Med Assoc. 89(6): 405-411.

Tobin, T., Downer, S., Prendergast, K. Marshall, M.B., Greenwald R., and Leib, E.B. Food banks as partners in health promotion: Creating connections for client \& community health. Feeding America and Center for Health Law and Public Policy Innovation/Harvard Law School. Accessed May 27, 2020. http://www.rootcausecoalition.org/wp-content/uploads/2016/07/ Food-Banks-as-Partners-in-Health-Promotion-FINAL.pdf

United States Department of Health and Human Services. (April 2011). HHS Action Plan to Reduce Racial and Ethnic Health Disparities. http://minorityhealth.hhs.gov/npa/files/plans/hhs/hhs_plan_com plete.pdf.

Wennerstrom, A., Vannoy, S.D., Allen, III , C.E., Meyers, D., O'Toole, E., Wells, K.B., \& Springgate, B.F. (2011). Community-Based participatory development of a community health worker mental health outreach role to extend collaborative care in post-Katrina New Orleans. Ethnicity and Disease. 21(3 0 1): S1-45-51.

Werner D. (1970). Where there is no doctor. Hesperian Health Guide.

Whitley EM, Everhart RM, \& Wright RA. (2006). Measuring return on investment of outreach by community health workers. Journal of the Health Care Poor Underserved. 17(1 Suppl):6-15. 
WHO (World Health Organization). (2012). What are the social determinants of health? Accessed June 9, 2020).

http://www.who.int/social_determinants/sdh_definition/en/

(C) Gail G. McCray, Berneta L. Haynes, Adrianne S. Proeller, Christopher E. Ervin, and Arletha D. Williams-Livingston. Originally published in jGPHA (http:/www.gapha.org/jgpha/) July 24, 2020. This is an open-access article distributed under the terms of the Creative Commons Attribution Non-Commercial No-Derivatives License (http://creativecommons.org/licenses/by/4.0/), which permits unrestricted use, distribution, and reproduction in any medium, provided the original work ("first published in the Journal of the Georgia Public Health Association...") is properly cited with original URL and bibliographic citation information. The complete bibliographic information, a link to the original publication on http://www.gapha.jgpha.org/, as well as this copyright and license information must be included. 